25 Running head: short-chain fructans and colitis Sugiyama, Ph.D. ${ }^{2}$, Shuhachi Kiriyama, Ph.D. ${ }^{4}$ and Tatsuya Morita, Ph.D. ${ }^{2 *}$

${ }^{1}$ Graduate School of Science and Technology, Shizuoka University, Shizuoka 422-8529, Japan Agriculture, Shizuoka University, 836 Ohya, Shizuoka 422-8529, Japan

${ }^{3}$ Fuji Nihon Seito Corporation, 1-4-10 Seikai, Shizuoka 424-8737, Japan.

Yada, Shizuoka 422-8526, Japan Ohya, Shizuoka 422-8529, Japan; Telephone/Fax:

2 81-54-238-5132

3 E-mail: actmori@agr.shizuoka.ac.jp 4 6

\title{
Short-chain Inulin-like Fructans Reduce Endotoxin and Bacterial Translocations and Attenuate the Development of TNBS-induced Colitis in Rats
}

Hiroyuki Ito, M.S. ${ }^{1}$, Hiroki Tanabe, Ph.D. ${ }^{2}$, Hirokazu Kawakishi, Ph.D. ${ }^{1}$, Wada Tadashi, Ph.D ${ }^{3}$., Tomono Yasuhiko, Ph.D ${ }^{3}$., Kimio

${ }^{2}$ Department of Applied Biological Chemistry, Faculty of

${ }^{4}$ Faculty of Nutritional Sciences, University of Shizuoka, 52-1

*For correspondence at: Department of Applied Biological Chemistry, Faculty of Agriculture, Shizuoka University, 836 
1 Abstract

2 Anti-inflammatory effects of short-chain inulin-like fructans

3 (SCF) on trinitrobenzene sulfonic acid (TNBS)-induced colitis

4 were investigated in rats, focusing specifically on endotoxin

5 and bacterial translocations. SCF with degrees of

6 polymerization (DP) of 4 and 8 were used. Rats were fed either

7 control diet or diets including $60 \mathrm{~g}$ of DP 4 or DP $8 / \mathrm{kg}$ for $7 \mathrm{~d}$,

8 and then received intracolonic TNBS and were fed the

9 respective diets for a further $10 \mathrm{~d}$. DP 4 and DP 8 significantly

10 reduced colonic injuries as assessed by damage score, but the

11 reduction of colonic myeloperoxidase activity was manifest

12 solely in DP8. At $3 \mathrm{~d}$ after colitis induction, bacterial

13 translocation to the mesenteric lymph node was significantly

14 lower in the DP4 and DP8 groups, but a significant reduction in

15 the portal endotoxin concentration was achieved solely in the

16 DP8 group. Immediately prior to colitis induction, cecal

17 immunogloblin A and mucin concentrations were higher in the

18 DP4 and DP8 groups, but these changes were abolished at 10d

19 post-colitis induction. The data suggest that SCF exert

20 prophylactic effects against TNBS colitis, presumably as a

21 result of inhibitory effects on endotoxin and bacterial

22 translocations.

24 KEY WORDS: short-chain fructans; endotoxin; bacterial

25 translocation; mucin; colitis. 


\section{Introduction}

2 Short-chain inulin-like fructans (SCF) have been identified as a

3 potential treatment strategy for inflammatory bowel disease,

4 with successful outcomes in trinitrobenzene sulfonic acid

5 (TNBS)-induced colitis in rats $[1,2]$. The mechanism involved

6 in the anti-inflammatory action of these oligosaccharides are

7 considered to have some general properties such as selective

8 stimulation of lactobacilli and bifidobacteria, reduction of

9 colonic $\mathrm{pH}$, and the maintenance of mucosal integrity due to

10 augmentation of cecal short-chain fatty acid (SCFA) production.

11 However, the precise mechanism has not yet been fully

12 elucidated.

14 Colitis, induced by intracolonic administration of TNBS in a

15 vehicle of ethanol, is in part due to the caustic properties of this

16 mixture, followed by exposure of the underlying lamina propria

17 to bacterial components. The colitis is also partly due to the

18 induction of an IL-12-driven inflammation with a Th1-mediated

19 response to TNBS-modified proteins [3, 4, 5]. In rats, however,

20 the inflammation pattern of the acute phase of colitis, at 1 to 2

21 wk after TNBS administration, has been shown to resemble

22 non-specific colitis induced by intracolonic acetic acid

23 administration $[5,6,7]$. Previous studies have shown that the

24 severity of the acute phase of TNBS colitis is correlated with

25 the concentration of systemic endotoxin as well as the extent of 
1 bacterial translocation [8,9]. Therefore, insofar as the acute

2 phase of colitis is concerned, reinforcement of mucosal barrier

3 function, including a reduction in colonic endotoxin

4 concentration, may be an important factor in the protection

5 against TNBS-induced colitis.

6

7 Previously, we examined cecal amounts of $\operatorname{IgA}$ and mucin in

8 rats fed inulin-like fructans with different degrees of

9 polymerization (DP) (average DP; 4, 8, 16, and 23). The results

10 indicated that while cecal mucin was likely to respond to cecal

11 SCFA, IgA increased when both fermentation occurred rapidly

12 and lactate was a major fermentation product [10].

13 Consequently, the cecal concentration of mucin increased

14 significantly in rats fed fructans with DP8, 16 and 23, whereas

15 IgA was higher in rats fed those with DP4 and 8 [10]. With

16 regard to the anti-inflammatory action against the acute phase

17 of the TNBS-induced colitis model, both luminal mucin and IgA

18 may play an important role in the protection against penetration

19 of luminal bacteria and endotoxin, presumably by limiting their

20 motility or access to the epithelial surface [11]. It is also

21 possible that the mucus layer serves as a binding site for

22 immunoglobulins, particularly for secretory IgA, and works in

23 cooperation with IgA [12]. In this regard, we hypothesize that

24 DP8 fructan, which has the potential to increase both luminal

25 mucin and IgA, might be a good candidate for the reinforcement 
1 of the mucosal barrier, thereby protecting against bacterial and

2 endotoxin translocations.

3

4 In previous studies that examined the effects of prebiotics,

5 including dietary fibers, the majority used the acute phase of

6 TNBS colitis in their evaluations [1, 2, 13]. However, limited

7 data are available in regards to the role of mucin and IgA in the

8 protection against endotoxin and bacterial translocations. The

9 purpose of the present study was to examine whether DP8

10 fructan reduces endotoxin and bacterial translocations and

11 exerts a prophylactic effect on the acute phase of TNBS colitis

12 in rats. The effects of DP8 were compared to an established

13 positive reference in this model, DP4, which is virtually the

14 same as fructooligosaccharides (FOS) $[1,2]$.

17 Methods

18 Materials

19 Inulin-like fructan, with an average degree of polymerization of 208 (DP8; range of DP, 5-13), was prepared by enzymatic synthesis

21 using a novel fungal enzyme, $\beta$-fructosidase, from Bacillus $s p$.

22 217C-11 as described previously [14]. Fructooligosaccharides

23 (DP4; average DP, 4) were purchased from Meiji Seika

24 (Meioligo ${ }^{\circledR}$ P, Tokyo, Japan). The composition of FOS was $44 \%$

25 1-kestose, $46 \%$ nystose, and 10\% 1-f- $\beta$-fructofuranosyl nystose. 
1 Animal care

2 Male F344 rats were purchased from Shizuoka Laboratory

3 Animal Center (Hamamatsu, Japan). They were individually

4 housed in screen-bottomed stainless steel cages in a

5 temperature- $\left(23 \pm 2{ }^{\circ} \mathrm{C}\right)$ and light- (lights on from 8:00 to

6 20:00) controlled room. For the purposes of adaptation, rats

7 were fed a control diet for at least $3 \mathrm{~d}$. This diet [15] was

8 formulated from $250 \mathrm{~g} / \mathrm{kg}$ casein, $652.25 \mathrm{~g} / \mathrm{kg}$ cornstarch and

$950 \mathrm{~g} / \mathrm{kg}$ corn oil. The remainder of the diet consisted of vitamins

10 and minerals [15]. The rats were then divided into groups based

11 on body weight and allowed free access to experimental diets

12 and water. Body weight and food intake were recorded each

13 morning before replenishing the diet. The study was approved

14 by the Animal Use Committee of Shizuoka University, and the

15 animals were maintained in accordance with the guidelines for

16 the care and use of laboratory animals, Shizuoka University.

18 Time course studies on portal endotoxin concentration and

19 bacterial translocation to the mesenteric lymph nodes (MLN)

20 post-TNBS administration (preliminary study)

21 Thirty rats weighing 154 to $175 \mathrm{~g}$ ( 8 wks old) were used. All

22 rats were fed the control diet throughout the experiment. After

23 being fed control diet for $7 \mathrm{~d}$, the rats were lightly anesthetized

24 with diethyl ether and then treated with an intracolonic

25 injection of $20 \%$ glycerin solution $(0.2 \mathrm{ml} / \mathrm{rat})$ using a 
1 lubricated polypropylene catheter (diameter $1.5 \mathrm{~mm}$ ) inserted 8

$2 \mathrm{~cm}$ into the colon via the anus. Preliminary results indicated

3 that this treatment was useful for removing the colonic contents.

4 Usually, defecation was completed within $15 \mathrm{~min}$, and the colon

5 was kept empty for at least $60 \mathrm{~min}$ after treatment. At $60 \mathrm{~min}$

6 after administration of the glycerin solution, the rats were

7 anesthetized with diethyl ether and given $30 \mathrm{mg}$ of TNBS

8 (dissolved in $0.25 \mathrm{ml}$ of $50 \%$ ethanol $(\mathrm{v} / \mathrm{v})$ ) via polypropylene

9 catheter, as described above, inserted $8 \mathrm{~cm}$ through the anus.

10 After instillation, the rats were kept in a vertical position for 30

$11 \mathrm{~s}$ and returned to their cages. At 1 and $6 \mathrm{~h}$ and 1,3 and $7 \mathrm{~d}$ after

12 instillation, the rats were anesthetized with diethyl ether and

13 underwent laparotomy under aseptic conditions. Portal blood

$14(300 \mu 1)$ was collected with a heparinized syringe. Following 15 centrifugation at $2000 \times g$ for $10 \mathrm{~min}$, plasma was obtained and 16 used for endotoxin measurement. Mesenteric lymph nodes were 17 also collected from the ileo-cecal junction at 1, 3 and $7 \mathrm{~d}$ after 18 instillation and used for bacterial translocation assessment.

19 Cecal fermentation, mucin and $\mathrm{Ig} A$ in rats fed the respective 20 diets pre-TNBS administration (experiment 1)

21 Twenty-four rats weighing 148 to $169 \mathrm{~g}$ ( $8 \mathrm{wk}$ old) were 22 acclimatized, then divided into 3 groups of 8 rats and allowed 23 free access to control or experimental diet (60 g of DP4 or 24 DP $8 / \mathrm{kg}$ ). Each of the test materials was substituted with the 25 same amount of cornstarch as in the control diet. After being 
1 fed the respective diets for $7 \mathrm{~d}$, the rats were anesthetized with

2 diethyl ether, and the cecum excised. The cecal contents were

3 removed, weighed and divided into two portions. One was

4 freeze-dried and used for mucin analysis, and the other was

5 used for the measurement of $\mathrm{pH}$, organic acids and $\operatorname{IgA}$.

6 Protective effects of DP4 and DP8 ingestion against

7 TNBS-induced colitis (experiment 2)

8 Forty-two rats weighting 149 to $177 \mathrm{~g}$ ( 8 wks old) were

9 acclimatized, then divided into 3 groups of 14 rats and allowed

10 free access to the same experimental diets as in experiment 1.

11 After being fed the respective diets for $7 \mathrm{~d}$, the rats were

12 administrated $20 \%$ glycerin, followed by TNBS $/ 50 \%$ ethanol in

13 the same manner as in the preliminary experiment. At $3 \mathrm{~d}$ after

14 instillation, 6 rats from each group were anesthetized with

15 diethyl ether, and portal blood and MLN were collected in the

16 same manner as in the preliminary experiment. The remaining 8

17 rats from each group continued to be fed the respective diets for

$1810 \mathrm{~d}$ after colitis induction. Feces were collected during the last

$193 \mathrm{~d}$. The fecal samples were prepared in the same manner as

20 cecal contents and used for the analysis of mucin and IgA. At

21 the end of the test period, the rats were anesthetized with

22 diethyl ether, and the cecum and colon were excised. The cecal

23 contents were handled in the same manner as experiment 1 . The

24 colon was cut open longitudinally and the colonic contents were

25 removed. The colon was then weighed, length measured and 
1 scored for macroscopically visible damage on a 0-10 scale by

2 two observers unaware of the treatment, according to the

3 criteria described by Bell et al. [16] (Table 1). The respective

4 whole colon specimens were divided longitudinally into two

5 fragments. One fragment was stored at $-80^{\circ} \mathrm{C}$ pending

6 measurement of myeloperoxidase (MPO) activity, and the other

7 fragment was fixed with $10 \%$ neutral buffered formalin and

8 embedded in paraffin. The sections embedded in paraffin were

9 cut at $4 \mu \mathrm{m}$ and stained with periodic acid-Schiff.

\section{Portal endotoxin}

12 Portal endotoxin was determined by the limulus amebocyte 13 lysate test [17], which involves a turbidimeteric time assay at $14450 \mathrm{~nm}$ with a toxinometer ET-2000 (Wako Pure Chemicals, 15 Osaka, Japan). The plasma sample was diluted ten-fold with 16 sterile water for injection (Otsuka Pharmaceutical Factory, Inc.,

17 Tokushima, Japan) and heated at $80^{\circ} \mathrm{C}$ for 5 min to deactivate 18 the lipopolysaccharide binding protein. The sample was then 19 mixed with limulus reagent (Wako Pure Chemicals, Osaka, 20 Japan) and applied to toxinometer analysis. Endotoxin prepared 21 from Escherichia coli O113:H10 (Wako Pure Chemicals, Osaka, 22 Japan) was used as the standard.

\section{Bacterial translocation to $M L N$}

24 MLNs were minced and homogenized in $0.5 \mathrm{~mL}$ of sterile Brain 25 Heart Infusion (BHI) broth (Wako Pure Chemicals, Osaka, 
1 Japan) by a hand-operated Polytron homogenizer. The

2 homogenate $(0.1 \mathrm{~mL})$ was inoculated onto BHI agar plates

3 (Wako Pure Chemicals, Osaka, Japan), which were subsequently

4 incubated under either aerobic or anaerobic conditions at $37^{\circ} \mathrm{C}$

5 for $72 \mathrm{~h}$. Duplicate assay was conducted. After incubation,

6 colonies were counted and the microorganisms were quantified

7 as colony forming units per gram $\left(\log _{10} \mathrm{CFU} / \mathrm{g}\right)$.

8 Cecal pH and organic acids

9 After the cecal contents were homogenized, a portion of the

10 homogenate was diluted with an equal weight of distilled water,

11 and cecal $\mathrm{pH}$ was measured with a compact $\mathrm{pH}$ meter (Model

12 C-1, Horiba, Tokyo, Japan). Cecal organic acids were measured

13 by the internal standard method [18] using HPLC (LC-10A,

14 Shimadzu, Kyoto, Japan) equipped with a Shim-pack SCR-102H

15 column $(8 \mathrm{~mm}$ i.d. $\times 30 \mathrm{~cm}$ long, Shimadzu $)$ and an

16 electroconductibity detector (CDD-6A, Shimadzu).

17 Secretory $\operatorname{IgA}$

18 Cecal IgA was determined by enzyme-linked immunosorbent

19 assay using Nunc-Immuno plates (MaxiSorb F96) and a slight

20 modification [19] of the method described by Grewal et al [20].

21 Assays were conducted in duplicate.

22 O-linked oligosaccharide chains

23 Mucins were extracted by the method of Bovee-Oudenhoven et al.

24 [21] with some modifications [22]. O-linked oligosaccharide

25 chains were determined as a mucin marker. After an appropriate 
1 dilution of the mucin fraction, $O$-linked oligosaccharide chains

2 were measured using a fluorimetric assay [23] that discriminated

$3 \quad O$-linked glycoproteins (mucin) from $N$-linked glycoproteins, as

4 described by Bovee-Oudenhoven et al. [21]. Standard solutions

5 of $N$-acetylgalactosamine (Sigma, St. Louis, MO, USA) were

6 used to calculate the quantity of oligosaccharide chains liberated

7 from mucins during the procedure.

$8 \quad$ Myeloperoxidase activity

9 Myeloperoxidase activity was determined by the method of

10 Bradley et al. [24]. Briefly, the colon was minced and

11 homogenized in $50 \mathrm{mmol} / 1$ potassium phosphate buffer ( $\mathrm{pH} 6.0)$

12 containing $0.5 \%$ hexadecyltrimethylammoniumbromide

13 (SIGMA, St Louis, MO, USA) by a polytron homogenizer.

14 Homogenate was subjected to three cycle of freeze-thawing and 15 sonication, and centrifuged at $20,000 \times g$ for $30 \mathrm{~min}$. The 16 supernatant was used to determine MPO activity utilizing $170.0005 \%$ hydrogen peroxide as a substrate for the MPO. A unit 18 of MPO activity was defined as that converting $1 \mu \mathrm{mol}$ of 19 hydrogen peroxide to water per $1 \mathrm{~min}$ at $25^{\circ} \mathrm{C}$.

\section{Statistical analyses}

21 Data were analyzed by one-way analysis of variance (ANOVA), 22 and significant differences among means were separated by the

23 Tukey-Kramer test. When variances were not homogeneous by

24 the Bartlett test [25], data were transformed logarithmically and 
1 then analyzed by ANOVA followed by multiple comparisons, or

2 analyzed by the Steel-Dwass test. Normally, results were

3 expressed as means with SEM, otherwise as median and range for

4 non-parametric data, and all statements of significant differences

5 reflected the 5\% level of probability. The Tukey-Kramer test and

6 the Bartlett test were performed using StatView 5.0 computer

7 software (SAS Institute, Cary, N.C., U.S.A.), and the

8 Steel-Dwass test and linear regression analyses were performed

9 using Excel Statistics program (version 6.0; Esumi, Tokyo,

10 Japan).

13 Results

14 Portal endotoxin and bacterial translocation post-TNBS

15 administration (preliminary experiment)

16 Before TNBS administration, the average body weight of rats

17 was $185 \pm 2$. After TNBS administration, food intake and body

18 weight decreased sharply for the first $3 \mathrm{~d}$ and then gradually

19 recovered in the following days (data not shown). Portal

20 endotoxin was detected beginning at $1 \mathrm{~h}$ after TNBS

21 administration, reached maximum at $\mathrm{d} 3$, and then decreased at

22 d 7. Bacterial counts in MLN reached maximum at $d$, and this

23 level persisted at d 7 (Figure 1).

25 Cecal fermentation, mucin and IgA pre-TNBS administration 


\section{1 (experiment 1)}

2 Food intake and body weight gain were significantly lower in

3 rats fed the DP4 and DP8 diets than in those fed the control diet,

4 however, no significant differences were detected between the

5 DP4 and DP8 diet-fed groups. The weights of cecal tissue and

6 cecal contents in rats fed the DP4 and DP 8 diets were

7 significantly higher than in those fed the control diet. Cecal $\mathrm{pH}$

8 declined significantly in the DP4 and DP8 diet-fed groups

9 (Table 2). The cecal concentrations of propionate, butyrate and

10 lactate differed among the groups. Propionate and butyrate

11 concentrations were higher in rats fed the DP4 and DP8 diets,

12 respectively. Cecal concentration of mucin was highest in the

13 DP8, intermediate in the DP4, and lowest in the control diet-fed

14 groups. Cecal concentration of IgA in rats fed the DP4 and DP8

15 diets was significantly higher than in those fed the control diets,

16 however, there were no differences detected between the DP4

17 and DP8 diet-fed groups (Table 2). Linear regression analysis

18 showed that the cecal concentrations of mucin and IgA were

19 significantly correlated with the cecal concentrations of

20 butyrate $(\mathrm{r}=0.57, \mathrm{P}=0.004)$ and lactate $(\mathrm{r}=0.57, \mathrm{P}=0.003)$,

21 respectively. No other correlations among the cecal

22 concentrations of organic acid, mucin and IgA were significant

23 (data not shown) in the present study.

24 Protective effects of DP4 and DP8 ingestion against

25 TNBS-induced colitis (experiment 2) 
1 Prior to TNBS administration, daily food intake and body

2 weight were significantly lower in rats fed the DP4 and DP8

3 diets than in those fed the control diet, however, no differences

4 were detected between the DP4 and DP8 diet-fed groups

5 (Figure 2-a, b). Post-TNBS administration, food intake and

6 body weight in all dietary groups decreased drastically for the

7 first $3 \mathrm{~d}$, and then gradually recovered in the following days.

8 From d5 to d10 after TNBS administration, food intake in rats

9 fed the DP4 and DP8 diets was significantly greater than in

10 those fed the control diet, and this difference was reflected in

11 the recovery rate of body weight gain among the groups (Figure 12 2-a, b).

13 At d 3 post-TNBS administration, portal endotoxin was detected

14 in all rats (6/ 6 rats) fed control diet and showed an average

15 concentration of $6.9 \pm 0.9 \mathrm{pg} / \mathrm{ml}$. However, the detection ratio in

16 rats fed DP4 and DP8 diets was reduced to $4 / 6$ and 1/6,

17 respectively. Further, portal endotoxin concentration in rats fed

18 DP8 diet was significantly lower than in those fed the control and

19 DP4 diets (Figure 3-a). Bacterial translocation into the MLN in

20 rats fed DP4 and DP8 diets was significantly reduced by $70 \%$ as

21 compared to that in rats fed control diet. (Figure 3-b).

22 At autopsy, the colonic mucosa in rats fed the control diet was

23 severely inflamed, as indicated by the macroscopic damage

24 score, relative colon weight and colonic MPO activity.

25 Compared with the control group, a significant reduction in the 
1 macroscopic damage score and relative colon weight was

2 observed in the DP4 and DP8 groups, while MPO activity was

3 significantly decreased solely in the DP8 group (Figure 4-a, b, 4 c).

5 Even after TNBS administration, the weights of cecal tissue and

6 cecal contents in rats fed the DP4 and DP8 diets were

7 significantly higher than in those fed the control diet. A weak but

8 significant decline of cecal $\mathrm{pH}$ was observed in the DP4 and DP8

9 diet-fed groups (Table 3). However, in contrast to the findings

10 obtained with rats before TNBS administration, cecal

11 concentrations of organic acids, mucin and IgA were comparable

12 among the groups. Fecal IgA concentration also did not differ

13 among the groups, but fecal mucin in rats fed the DP8 diet was

14 significantly greater than in those fed the control diet (Table 3).

15 The histological appearance of inflammatory lesions showed

16 that as well as an intensive infiltration of granulocytes into the

17 mucosal tissue, loss of goblet cells was manifest in rats fed the

18 control diet. Compared with those fed control diet, the mucosal

19 integrity was apparent from the morphological features of

20 goblet cells in rats fed DP4 and DP8 diets (Figure 5-a, b, c).

\section{Discussion}

24 As expected from the previous study [10], prior to induction of 25 colitis, cecal concentration of mucin was highest in the DP8, 
1 intermediate in the DP4, and lowest in the control diet-fed groups,

2 whereas those of IgA in rats fed either DP4 or DP 8 diet were

3 elevated to an equal extent compared to those fed the control

4 diet (Table 2). Pretreatment with DP4 or DP8, initiated $7 \mathrm{~d}$

5 prior to TNBS administration, reduced colonic inflammation at

$610 \mathrm{~d}$ post-TNBS administration, as assessed by the macroscopic

7 damage score, relative colon weight and colonic MPO activity

8 (a marker of neutrophil infiltration) (Figure 4). Furthermore,

9 bacterial translocation to the MLN at $3 \mathrm{~d}$ post-colitis induction

10 was significantly reduced in rats fed either the DP4 or DP 8 diet

11 as compared to those fed the control diet, whereas a significant

12 reduction in the portal endotoxin concentration was observed

13 only in rats fed the DP8 diet (Figure 3 ). To our knowledge, this

14 is the first time that the ingestion of SCF reduced the systemic

15 endotoxin concentration in TNBS-colitis rats.

17 It has been shown that TNBS itself deteriorates mucosal barrier

18 function by interacting with surface-active phospholipids of the

19 colonic mucosa [3]. Shortly after intracolonic administration,

20 TNBS reduces surface hydrophobicity and increases tissue

21 susceptibility to bacteria and endotoxin, leading to an

22 inflammatory cascade, including the release of inflammatory

23 cytokines such as IL-1 $\beta$, IL- 6 , and TNF- $\alpha[6,9]$. The present

24 results, in this model, are largely in accordance with the

25 findings of Gardiner et al. [8], reporting that the severity of 
1 acute phase inflammation in TNBS colitis was correlated with

2 the degree of bacterial translocation and the concentration of

3 systemic endotoxin. In fact, the ingestion of DP8, which

4 dramatically reduced the portal endotoxin concentration, as

5 well as bacterial translocation to the MLN (Figure 3), showed

6 the strongest inhibitory effects on the induction of colonic MPO

7 activities (Figure 4-C). The precise mechanism by which DP8

8 ingestion reduced portal endotoxin concentration is not fully

9 elucidated. However, Enss et al. [26] showed that mucins

10 attached to the epithelial surface, as well as mixed to luminal

11 contents, possessed a binding capacity for E. coli that may act

12 as an endotoxin reservoir. Because the cecal mucin

13 concentration immediately prior to TNBS administration was

14 highest in rats fed DP8 diet (Table 2), it is possible to assume

15 that the increased concentration of cecal mucin could be

16 responsible for decreasing the permeability to endotoxin.

17 Another possible explanation may exist in the lactic

18 acid-bacteria inducing property of SCF [27, 28]. Bifidobacteria

19 have been shown to reduce intestinal endotoxin levels [29, 30],

20 while it has been suggested that lactobacilli possess the

21 potential ability to bind endotoxin [31]. It is also reasonable to

22 assume that higher concentrations of the cecal IgA in rats fed

23 the DP4 and DP8 diets may cooperate with luminal mucin and

24 contribute to protect the bacterial translocation to MLN (12). 
1 Interestingly, at $10 \mathrm{~d}$ post-TNBS administration, the beneficial

2 effects of DP4 and DP8 on cecal SCFA, lactate, $\mathrm{pH}$, mucin and

3 IgA were totally abolished, and there were no differences in

4 these variables among the groups. There is a number of

5 evidence that induction of colitis by this method is associated

6 with a significant increase in the number of aerobic

7 Gram-negative bacilli in the large bowel $(32,33)$. This might

8 affect the fermentation pattern of SCF and lead the decreased

9 concentrations of cecal SCFA, mucin, and IgA. Our results

10 differ from those of Cherbut et al. [1], showing lower $\mathrm{pH}$, and

11 higher lactate and butyrate in rats fed FOS (virtually the same

12 as DP4) at $7 \mathrm{~d}$ post-TNBS administration. The reason for this

13 remains unclear, but could be partly explained by differences in

14 the DP4 treatment method (i.e., dietary inclusion in the present

15 study or intragastric infusion) [1]. Nevertheless, the lack of

16 beneficial effects on cecal variables post-TNBS administration

17 suggests that the anti-inflammatory effects of DP4 and 8 might

18 be exerted through a shield-like effect against endotoxin and

19 bacterial translocations at the very early stage of TNBS colitis,

20 leading to reduced colonic damage at $10 \mathrm{~d}$ post-TNBS

21 administration. Consequently, at least under the present

22 experimental condition, the anti-inflammatory effects of SCF

23 are likely to be prophylactic.

25 Generally, two mechanisms have been considered in explaining 
1 the beneficial effects of SCF on colonic inflammation: changes

2 in the intestinal microflora, which stimulate selective growth of

3 lactic acid-bacteria, and an increase in colonic SCFA

4 concentration $[1,2,34]$. In this regard, Cherbut et al. [1]

5 suggested that the capacity of FOS to increase lactobacilli

6 counts was the main mechanism explaining its

7 anti-inflammatory effect, rather than the increment in SCFA

8 production. Indeed, lactic acid-bacteria evoke a local immune

9 stimulus to increase the levels of luminal secretory $\operatorname{IgA}[10,35]$

10 and anti-inflammatory cytokine, like IL-10 [36]. Furthermore,

11 the selective growth of lactic acid-bacteria could reduce the

12 number of Gram-negative bacilli that may serve as an endotoxin

13 reservoir, as discussed above. While, the present results suggest

14 that the protective effects against endotoxin influx by DP 8

15 ingestion are likely to be largely dependent on the

16 SCFA-stimulated increases in cecal mucin secretion

17 (particularly butyrate) [32, 37, 38]. In fact, cecal mucin

18 concentration in rats fed the control, DP4 and DP8 diets was

19 significantly correlated with cecal butyrate concentration

20 (Table 2). Therefore, it is possible to consider that an increase

21 in colonic butyrate may also be necessary for the

22 anti-inflammatory effects of SCF.

24 In conclusion, both the SCF of DP8 and DP4 exerted a

25 prophylactic effect on the acute phase of TNBS-induced colitis 
1 in rats, possibly through reduction of bacterial and endotoxin

2 translocations to the MLN. Compared with DP4, the greater

3 inhibitory effect of DP8 on endotoxin influx from the intestine

4 might be linked to the greater anti-inflammatory effects of DP8,

5 presumably as a result of a greater concentration of cecal

6 mucin.

7

8

9

10

11

12

13

14

15

16

17

18

19

25 References 
1 1. Cherbut C, Michel C, Lecannu G (2003) The prebiotic characteristics of fructooligosaccharides are necessary for reduction of TNBS-induced colitis in rats. J Nutr 133: 21-27

2. Lara-Villoslada F, de Haro O, Camuesco D, Comalada M, Zarzuelo A, Xaus J, Galvez J (2006) Short-chain fructooligosaccharides, in spite of being fermented in the upper part of the large intestine, have anti-inflammatory activity in the TNBS model of colitis. Eur J Nutr 45: $418-425$

3. Tatsumi Y, Lichtenberger LM (1996) Molecular association of trinitrobenzenesulfonic acid and surface phospholipids in the development of colitis in rats. Gastroenterology 110: $780-789$

4. Neurath MF, Fuss I, Kelsall BL, Stuber E, Strober W (1995) Antibodies to interleukin 12 abrogate established experimental colitis in mice. J Exp Med 182: 1281-1290

5. Gardiner KR, Rowlands BJ, Barbul A (1995) Colitis and colonic mucosal barrier dysfunction. Gut 37: 530-535

6. Sun FF, Lai P-S, Yue G, Yin K, Nagele RG, Tong DM, Krzesicki RF, Chin JE, Wong PY-K (2001) Pattern of cytokine and adhesion molecule mRNA in hapten-induced relapsing colon inflammation in the rats. Inflammation 25: $33-45$

7. Wallace JL, Mcknight W, Asfaha S, Liu DY (1998) Reduction of acute and reactivated colitis in rats by an 
inhibitor of neutrophil activation. Am J Physiol 274: G802-G808

8. Gardiner KR, Erwin PJ, Anderson NH, Barr JG, Halliday MI, Rowlands BJ (1993) Colonic bacteria and bacterial translocation in experimental colitis. Br J Surg 80: 512-516

9. Neilly PJD, Gardiner KR, Kirk SJ, Jennings G, Anderson NH, Elia M, Rowlands BJ (1995) Endotoxaemia and cytokine production in experimental colitis. Br J Surg 82: 1479-1482

10. Ito H, Wada T, Ohguchi M, Sugiyama K, Kiriyama S, Morita $\mathrm{T}$ (2008) The degree of polymerization of inulin-like fructans affects cecal mucin and immunogloblin $\mathrm{A}$ in rats. $\mathrm{J}$ Food Sci 73: 36-41

11. Deplancke B, Gaskins HR (2001) Microbial modulation of innate defense: goblet cells and the intestinal mucus layer. Am J Clin Nutr 73: 1131S-1141S

12. Mayer L (2003) Mucosal immunity. Pediatrics 111: $1595-1600$

13. Rodriguez-Cabezas ME, Galvez J, Lorente MD, Concha A, Camuesco D, Azzouz S, Osuna A, Redondo L, Zarzuelo A (2002) Dietary fiber down-regulates colonic tumor necrosis factor $\alpha$ and nitric oxide production in trinitrobenzenesulfonic acid-induced colitic rats. J Nutr 132: $3263-3271$

14. Wada T, Ohguchi M, Iwai Y (2003) A novel enzyme of 
1 Bacillus sp. $217 \mathrm{C}-11$ that produces inulin from sucrose.

2 Biosci Biotechnol Biochem 67(6):1327-34

3 15. Morita T, Kasaoka S, Ohhashi A, Ikai M, Numasaki Y,

4 Kiriyama S (1998) Resistant proteins alter cecal short-chain fatty acid profiles in rats fed high amylose cornstarch. J Nutr 128(7):1156-64

16. Bell CJ, Gall DG, Wallace IL (1995) Disruption of colonic electrolyte transport in experimental colitis. Am J Physiol 268: G622-G630

17. Levin J, Bang F.B. (1968) Clottable protein in Limulus: its localization and kinetics of its coagulation by endotoxin. Thromb Diath Haemorrh 19: 186-197

18. Morita T, Kasaoka S, Hase K, Kiriyama S (1999) Psyllium shifts the fermentation site of high amylose cornstarch toward the distal colon and increases fecal butyrate concentration in rats. J Nutr 129: 2081-2087

19. Morita T, Tanabe H, Sugiyama K, Kasaoka S, Kiriyama S (2004) Dietary resistant starch alters the characteristics of colonic mucosa and exerts a protective effect on trinitrobenzene sulfonic acid-induced colitis in rats. Biosci Biotechnol Biochem 68(10):2155-2164

20. Grewal HM, Hemming Karlsen T, Vetvik H, Ahr C, Gjessing HK, Sommerfelt H, Haneberg B (2000) Measurement of specific IgA in faecal extracts and intestinal lavage fluid for monitoring of mucosal immune 
responses. J Immunol Methods 239: 53-62

21. Bovee-Oudenhoven IM, Termont DS, Heidt PJ, Van der Meer R (1997) Increasing the intestinal resistance of rats to the invasive pathogen Salmonella enteritidis: additive effects of dietary lactulose and calcium. Gut 40(4): 497-504

22. Tanabe H, Sugiyama K, Matsuda T, Kiriyama S, Morita T (2005) Small intestinal mucins are secreted in proportion to the settling volume in water of dietary indigestible components in rats. J Nutr 135: 2431-2437

23. Crowther RS, Wetmore RF (1987) Fluorometric assay of O-linked glycoproteins by reaction with 2-cyanoacetamide. Analytical Biochem 163(1):170-174

24. Bradley PP, Priebat DA, Christensen RD, Rothstein G (1982) Measurement of cutaneous inflammation: estimation of neutrophil content with an enzyme marker. J Invest Dermatol 78: 206-209

25. Zar, J.H., Biostatistical Analysis, 2nd ed. Prentice-Hall, Englewood Cliffs, NJ. 1984

26. Enss ML, Muller H, Schmidt-Wittig U, Kownatzki R, Coenen M, Hedrich HJ (1996) Effects of perorally applied endotoxin on colonic mucins of germfree rats. Scand $\mathrm{J}$ Gastroenterol 31:868-874

27. Kleessen B, Hartmann L, Blaut M (2001) Oligofructose and long-chain inulin: influence on the gut microbial ecology of rats associated with a human faecal flora. Br J Nutr 
86(2): 291-300

28. Le Blay G, Michel C, Blottiere HM, Cherbut C (1999) Prolonged intake of fructo-oligosaccharides induces a short-term elevation of lactic acid-producing bacteria and a persistent increase in cecal butyrate in rats. J Nutr 129(12): 2231-2235

29. Wang Z, Xiao G, Yao Y, Guo S, Lu K, Sheng Z (2006) The role of bifidobacteria in gut barrier function after thermal injury in rats. J Trauma 61: 650-657

30. Wang Z, Yao Y, Xiao G, Sheng Z (2004) Risk factors of development of gut-derived bacterial translocation in thermally injured rats. World J Gastroenterol 10: 1619-1624

31. EI-Nezami H, Polychronaki N, Salminen S, Mykkanen H (2002) Binding rather than metabolism may explain the interaction of two food grade Lactobacillus strains with zearalenone and its derivative (') alpha-earalenol. Appl Environ Microbiol 68: 3545-3549

32. Lamine F, Eutamene H, Fioramonti J, Bueno L, Theodorou V (2004) Colonic responses to Lactobacillus farciminis treatment in trinitrobenzene sulphonic acid-induced colitis in rats. Scand J Gastroentorol 39: 1250-1258

33. Gardier KR, Erwin PJ, Anderson NH, McCaigue MD, Halliday MI, Rowlands BJ (1995) Lactulose as an antiendotoxin in experimental colitis. Brit J Surg 82: 469-472 
1 34. Holma R, Juvonen P, Asmawi MZ, Vapaatalo H, Korpela R (2002) Galacto-oligosaccharides stimulate the growth of bifidobacteria but fail to attenuate inflammation in experimental colitis in rats. Scand J Gastroenterol 37: $1042-1047$

35. Hosono A, Ozawa A, Kato R, Ohnishi Y, Nakanishi Y, Kimura T, Nakamura R (2003) Dietary fructooligosaccharides induce immunoregulation of intestinal IgA secretion by murine Peyer's patch cells. Biosci Biotechnol Biochem 67(4): 758-764

36. Barcelo A, Claustre J, Moro F, Chayvialle JA, Cuber JC, Plaisancie P (2000) Mucin secretion is modulated by luminal factors in the isolated vascularly perfused rat colon. Gut 46(2): 218-224

37. Finnie I, Dwarakanath A, Taylor B, Rhodes J (1995) Colonic mucin synthesis is increased by sodium butyrate. Gut 36: 93-99

38. Toden S, Bird AR, Topping DL, Conlon MA (2007) Dose-dependent reduction of dietary protein-induced colonocyte DNA damage by resistant starch in rats correlates more highly with caecal butyrate than with other short chain fatty acids. Cancer Biol Ther 6(2): 253-258 

Table 1
Criteria for assessment of macroscopic damage score

\begin{tabular}{ll}
\hline Score & Criteria \\
\hline 0 & No damage \\
1 & Hyperemia, no ulcers \\
2 & Linear ulcer with no significant inflammation \\
3 & Linear ulcer with inflammation at one site \\
4 & $\begin{array}{l}\text { Two or more sites of ulceration/inflammation } \\
5\end{array}$ \\
& $\begin{array}{l}\text { Two or more sites of ulceration and } \\
\text { inflammation or one site of } \\
\text { ulceration/inflammation extending }>1 \mathrm{~cm} \text { along } \\
\text { the length of the colon }\end{array}$ \\
& $\begin{array}{l}\text { If damage covers }>2 \text { cm along the length of } \\
\text { colon, the score is increased by } 1 \text { for each } \\
\text { additional centimeter of involvement }\end{array}$ \\
&
\end{tabular}


Table 2

Food intake and body weight gain, and cecal concentrations of organic acids,

mucin and IgA in rats fed the respective diet for $7 \mathrm{~d}$ (experiment 1 )

\begin{tabular}{lccc}
\hline & Control & DP4 & DP8 \\
\hline Food intake, g/7 d & $118.8 \pm 2.4^{\mathrm{b}}$ & $100.2 \pm 2.4^{\mathrm{a}}$ & $99.1 \pm 2.9^{\mathrm{a}}$ \\
Body weight gain, g/7 d & $29.9 \pm 1.5^{\mathrm{b}}$ & $24.1 \pm 1.7^{\mathrm{ab}}$ & $21.2 \pm 1.8^{\mathrm{a}}$ \\
Cecum & & & \\
$\quad$ Tissue, g & $0.4 \pm 0.0^{\mathrm{a}}$ & $1.0 \pm 0.1^{\mathrm{b}}$ & $1.0 \pm 0.0^{\mathrm{b}}$ \\
Contents, g & $1.7 \pm 0.0^{\mathrm{a}}$ & $3.5 \pm 0.3^{\mathrm{b}}$ & $3.0 \pm 0.1^{\mathrm{b}}$ \\
$\mathrm{pH}$ & $7.4 \pm 0.1^{\mathrm{b}}$ & $6.0 \pm 0.1^{\mathrm{a}}$ & $5.9 \pm 0.1^{\mathrm{a}}$ \\
Organic acids, $\mu$ mol/g & & & \\
$\quad$ Acetate & $38(31-53)$ & $20(9-89)$ & $30(16-80)$ \\
$\quad$ Propionate & $14(11-15)^{\mathrm{a}}$ & $22(14-82)^{\mathrm{b}}$ & $21(11-59)^{\mathrm{ab}}$ \\
$\quad$ n-Butyrate & $3(2-3)^{\mathrm{a}}$ & $6(2-25)^{\mathrm{b}}$ & $15(9-27)^{\mathrm{b}}$ \\
$\quad$ Total SCFA & $54(48-67)$ & $49(26-196)$ & $61(45-164)$ \\
$\quad$ Lactate & $0(0-18)^{\mathrm{a}}$ & $38(13-102)^{\mathrm{b}}$ & $24(0-127)^{\mathrm{b}}$ \\
$\quad$ Succinate & $16 \pm 5$ & $16 \pm 5$ & $26 \pm 6$ \\
Mucin, $\mu$ mol/g & $0.4 \pm 0.0^{\mathrm{a}}$ & $0.7 \pm 0.1^{\mathrm{b}}$ & $1.2 \pm 0.2^{\mathrm{c}}$ \\
IgA, $\mu$ gg/g & $132.8 \pm 23.8^{\mathrm{a}}$ & $793.5 \pm 169.3^{\mathrm{b}}$ & $542.3 \pm 99.7^{\mathrm{b}}$ \\
\hline
\end{tabular}

Data are expressed as mean $\pm \mathrm{SE}$ or median (range), $\mathrm{n}=8$. Values not sharing a common superscript letter are significantly different when analyzed by the Tukey-Kramer test (parametric data) or the Steel-Dwass test (non-parametric data).

${ }^{1}$ Degree of polymerization. ${ }^{2}$ Sum of acetate, propionate and n-butyrate. 


\section{Table 3}

Cecal concentrations of organic acids, mucin and IgA, and fecal concentrations of mucin and IgA

in rats fed the experimental diets at 10d after TNBS administration (experiment 2)

\begin{tabular}{lccc}
\hline & Control & DP4 & DP8 \\
\hline Cecum & & & \\
Tissue, g & $0.5 \pm 0.0^{\mathrm{a}}$ & $0.9 \pm 0.0^{\mathrm{b}}$ & $0.9 \pm 0.0^{\mathrm{b}}$ \\
Contents, g & $1.9 \pm 0.1^{\mathrm{a}}$ & $4.3 \pm 0.3^{\mathrm{b}}$ & $4.9 \pm 0.2^{\mathrm{b}}$ \\
pH & $7.8 \pm 0.1^{\mathrm{b}}$ & $7.4 \pm 0.1^{\mathrm{a}}$ & $7.3 \pm 0.1^{\mathrm{a}}$ \\
Organic acids, $\mu \mathrm{mol} / \mathrm{g}$ & & & \\
$\quad$ Acetate & $60 \pm 8$ & $52 \pm 9$ & $57 \pm 3$ \\
$\quad$ Propionate & $46(11-58)^{\mathrm{ab}}$ & $26(20-75)^{\mathrm{b}}$ & $19(15-25)^{\mathrm{a}}$ \\
n-Butyrate & $8(2-15)$ & $9(7-20)$ & $7(5-9)$ \\
Total SCFA & $105 \pm 17$ & $102 \pm 14$ & $83 \pm 5$ \\
$\quad$ Lactate & 0 & 0 & 0 \\
Succinate & $13 \pm 4$ & $23 \pm 4$ & $20 \pm 7$ \\
Mucin, $\mu$ mol/g & $0.4 \pm 0.1$ & $0.5 \pm 0.0$ & $0.5 \pm 0.0$ \\
IgA, $\mu \mathrm{g} / \mathrm{g}$ & $103 \pm 9$ & $55 \pm 4$ & $61 \pm 6$ \\
Feces & & & \\
Mucin, $\mu \mathrm{mol} / \mathrm{g}$ & $1.2 \pm 0.1^{\mathrm{a}}$ & $1.6 \pm 0.2^{\mathrm{ab}}$ & $2.0 \pm 0.2^{\mathrm{b}}$ \\
IgA, $\mu \mathrm{g} / \mathrm{g}$ & $79 \pm 23$ & $64 \pm 18$ & $47 \pm 11$ \\
\hline
\end{tabular}

The data are expressed as mean \pm SE or median (range), $n=8$. Values not sharing a common superscript letter are significantly different when analyzed by the Tukey-Kramer test (parametric data) or the Steel-Dwass test

24 (non-parametric data). ${ }^{1}$ Degree of polymerization. ${ }^{2}$ Sum of acetate, propionate and n-butyrate. 


\section{Figure legend}

Figure 1.

Changes in portal endotoxin concentration (a) and bacterial translocation to MLN (b) in rats post-TNBS administration

Data are expressed as mean $\pm S E(n=5)$.

N.D.: not detected.

Figure 2.

Changes in body weight (a) and daily food intake (b) in rats fed the respective diets pre- and post-TNBS administration

Data are expressed as mean $\pm \mathrm{SE}(\mathrm{n}=8)$.

* $\mathrm{P}<0.05$ vs. DP4. $\quad \mathrm{P}<0.05$ vs. DP8.

Figure 3.

Portal endotoxin concentration (a) and bacterial translocation to MLN (b) in rats fed the respective diets at $3 \mathrm{~d}$ post-TNBS administration

Data are expressed as mean \pm SE, values with different superscript letters are significantly different when analyzed by one-way ANOVA, followed by Tukey Kramer.

Figure 4.

Macroscopic damage score (a), relative colon weight (b) and MPO activity

(c) in rats fed the respective diets at $10 \mathrm{~d}$ post-TNBS administration

Data are expressed as mean $\pm S E(n=8)$, values with different superscript letters are significantly different when analyzed by one-way ANOVA, followed by Tukey Kramer.

Figure 5.

Histological appearance of colonic lesions in rats fed the respective diets at $10 \mathrm{~d}$ post-TNBS administration

a, control; b, DP4; c, DP8 
a

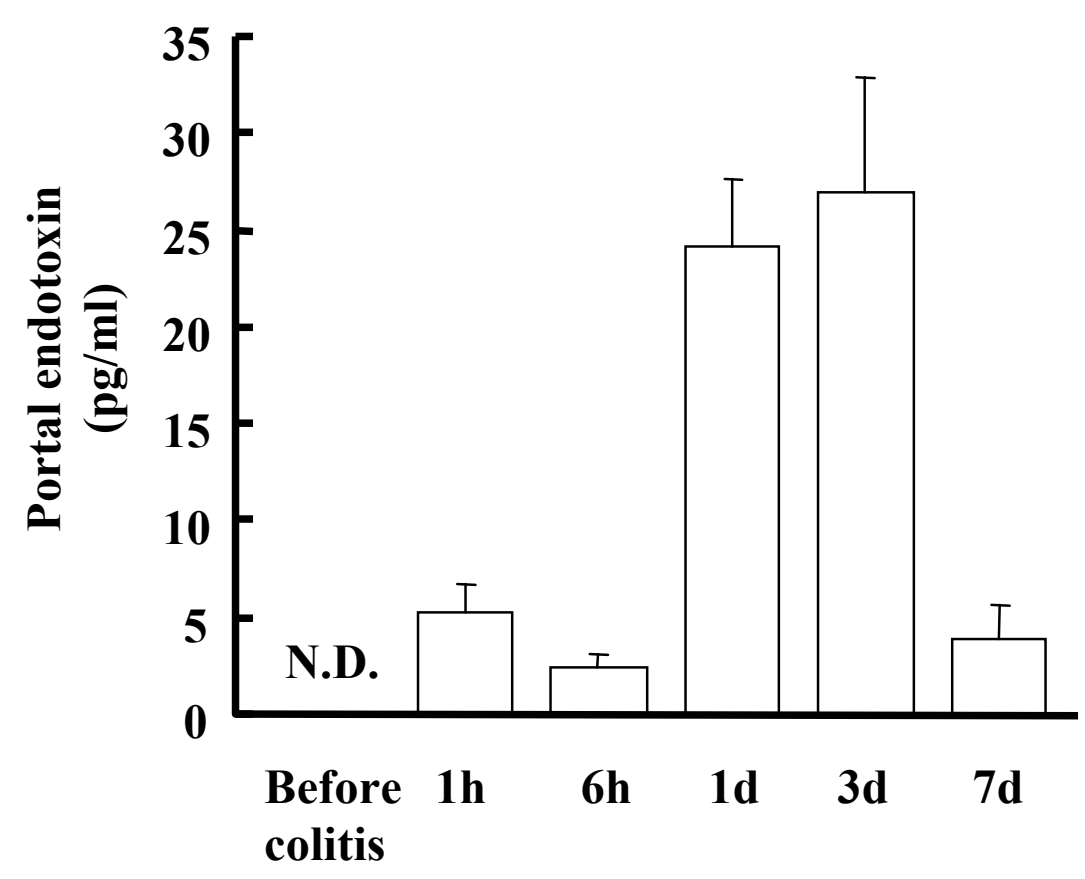

b

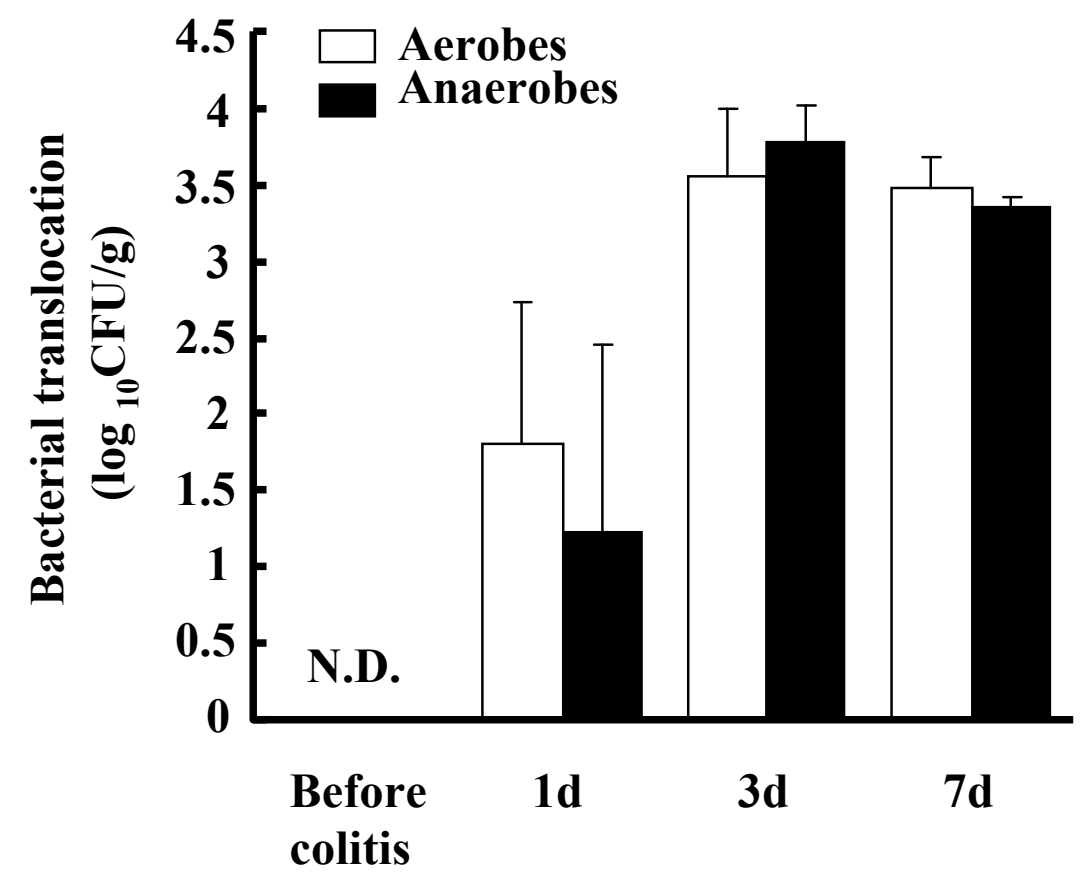

Fig.1 
a

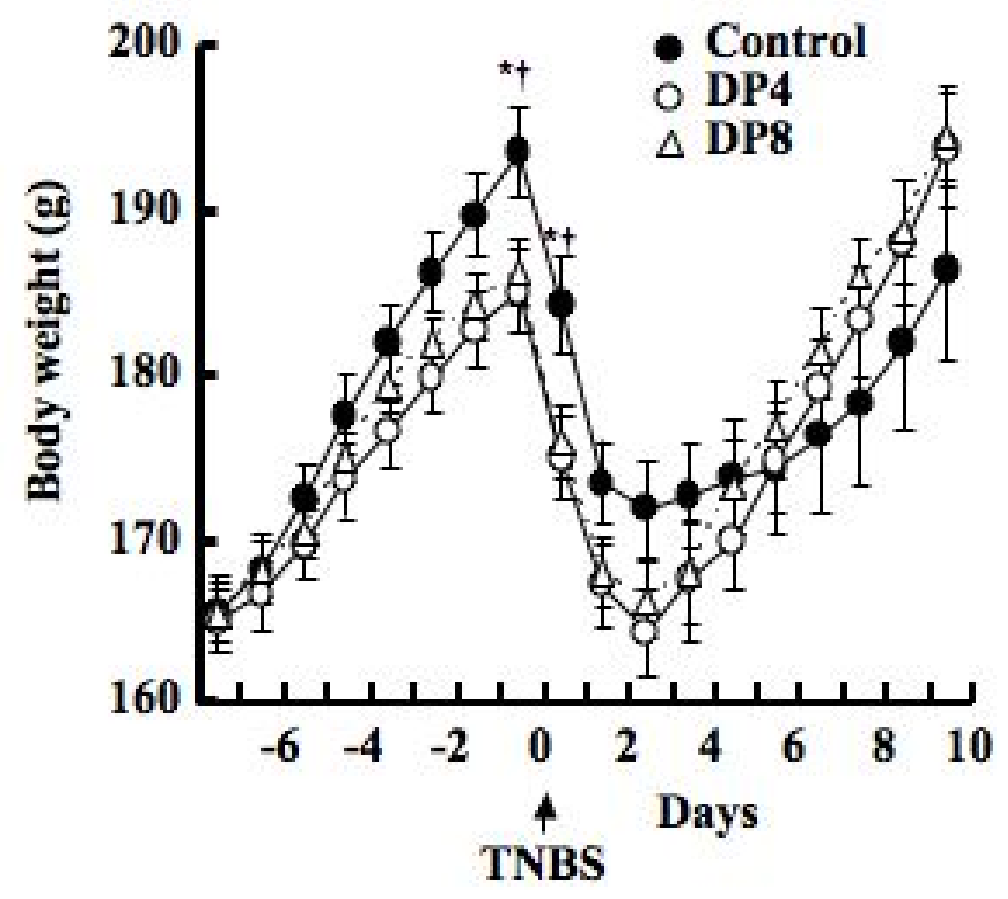

b

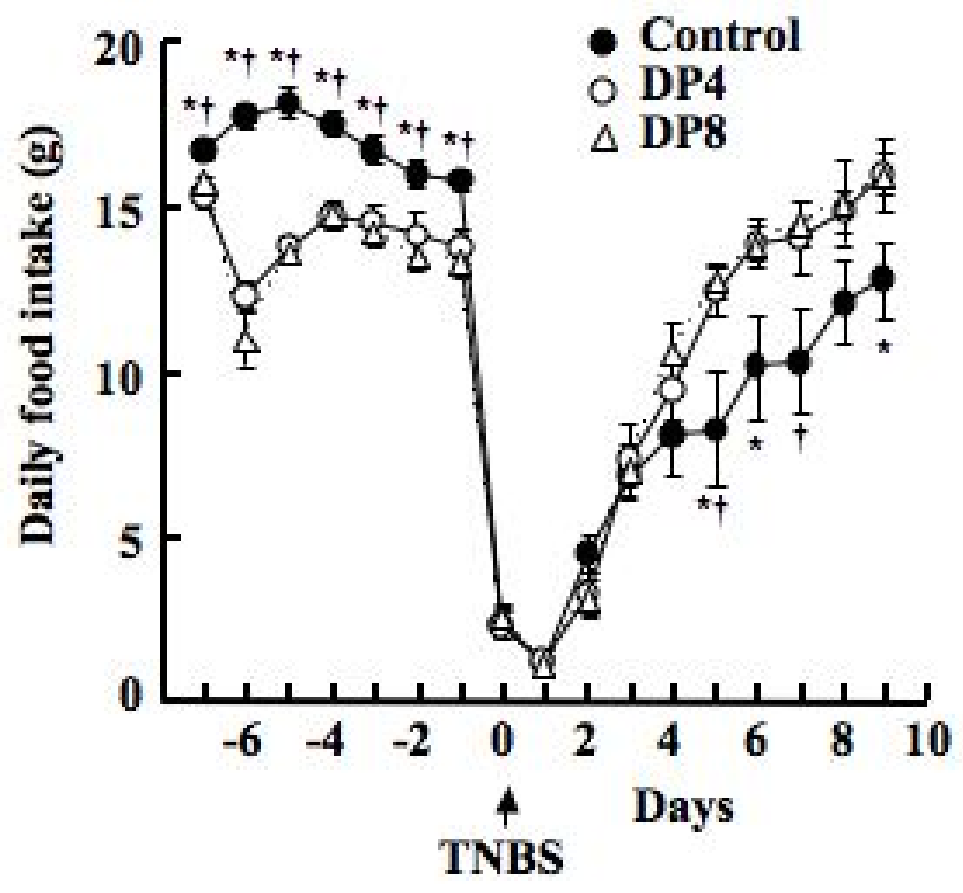

Fig.2 
a

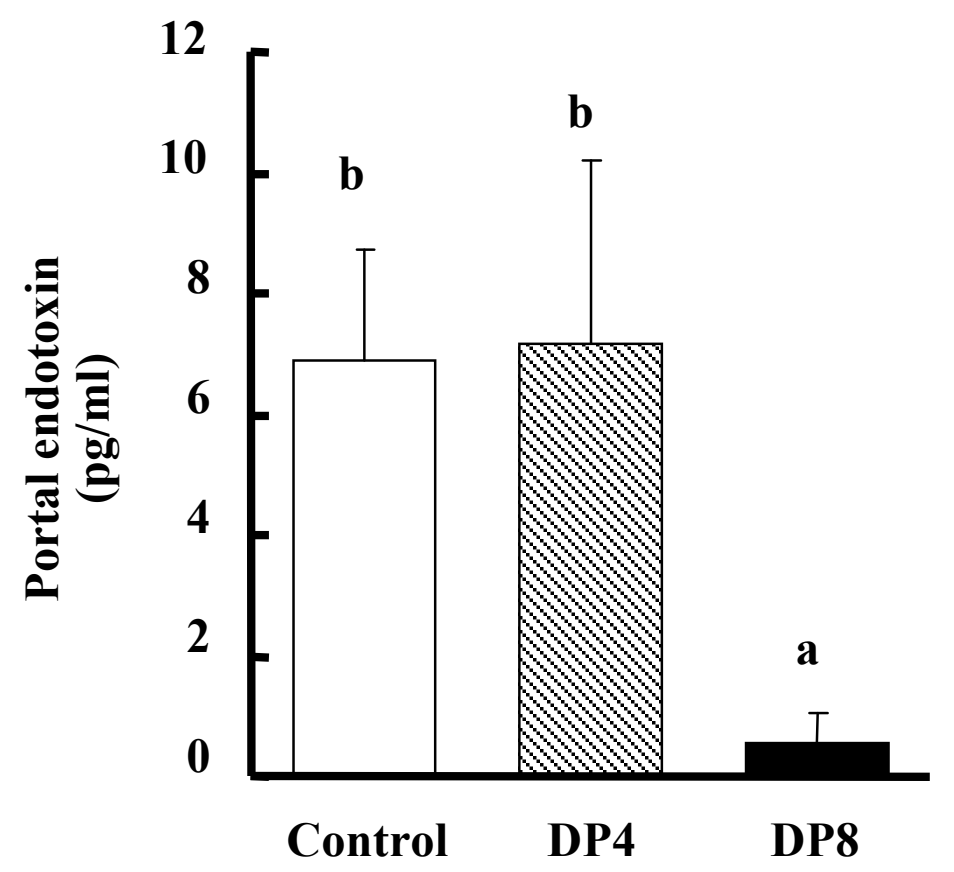

b

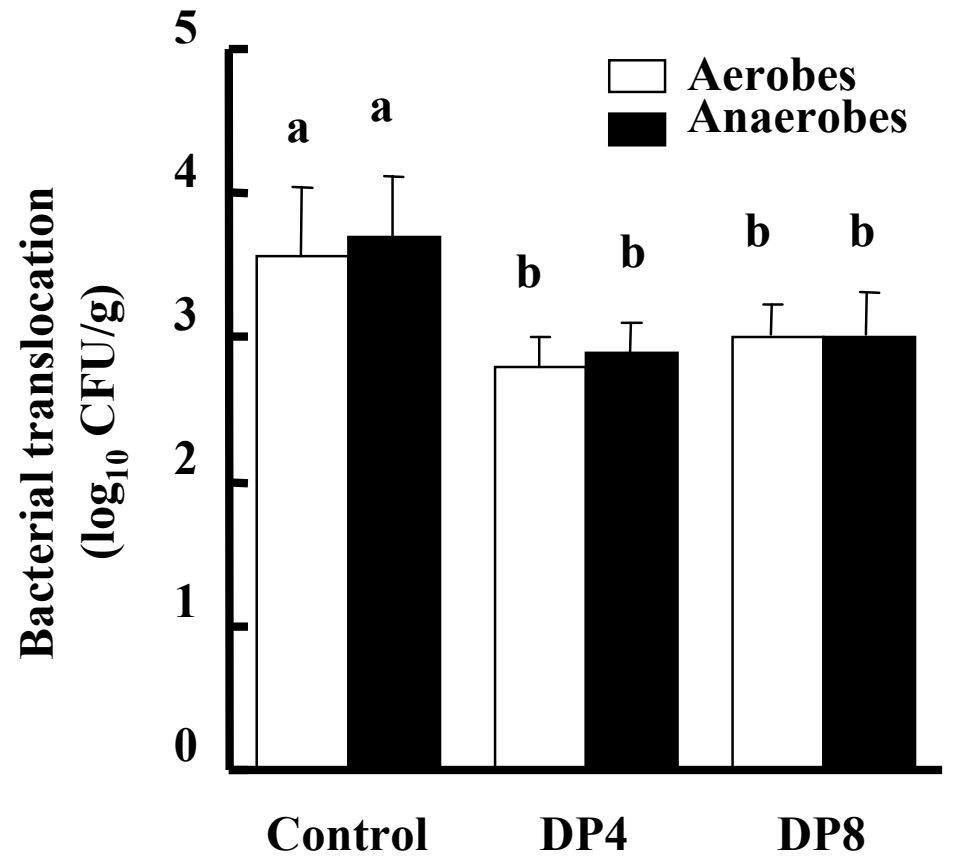

Fig.3 
a

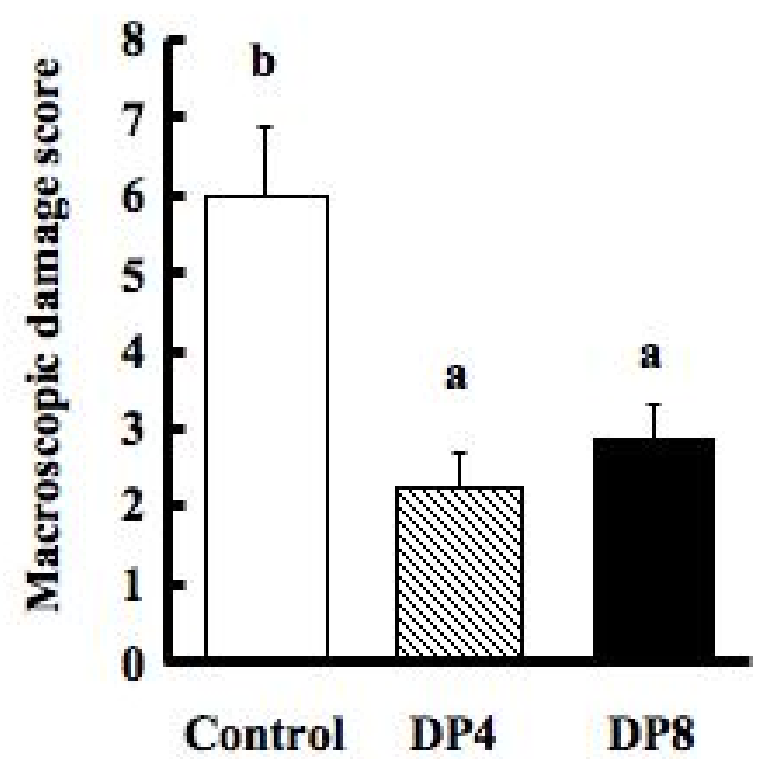

b

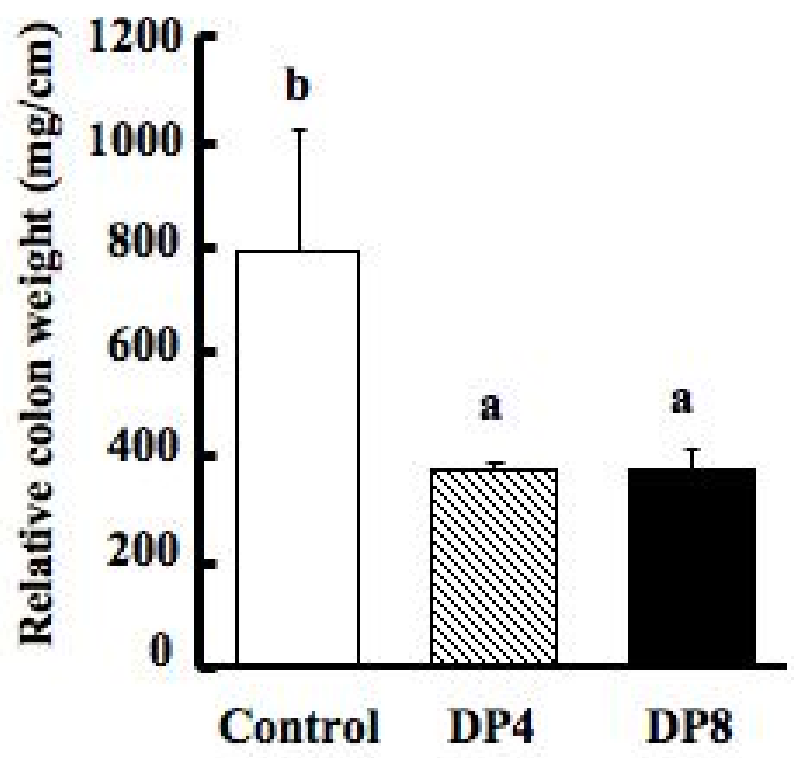

c

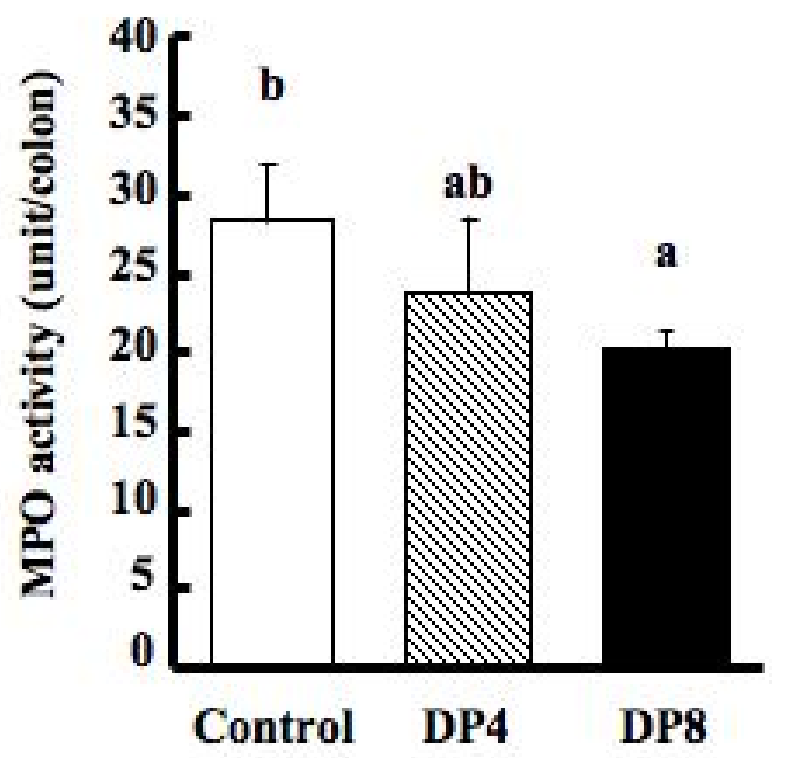

Fig.4 

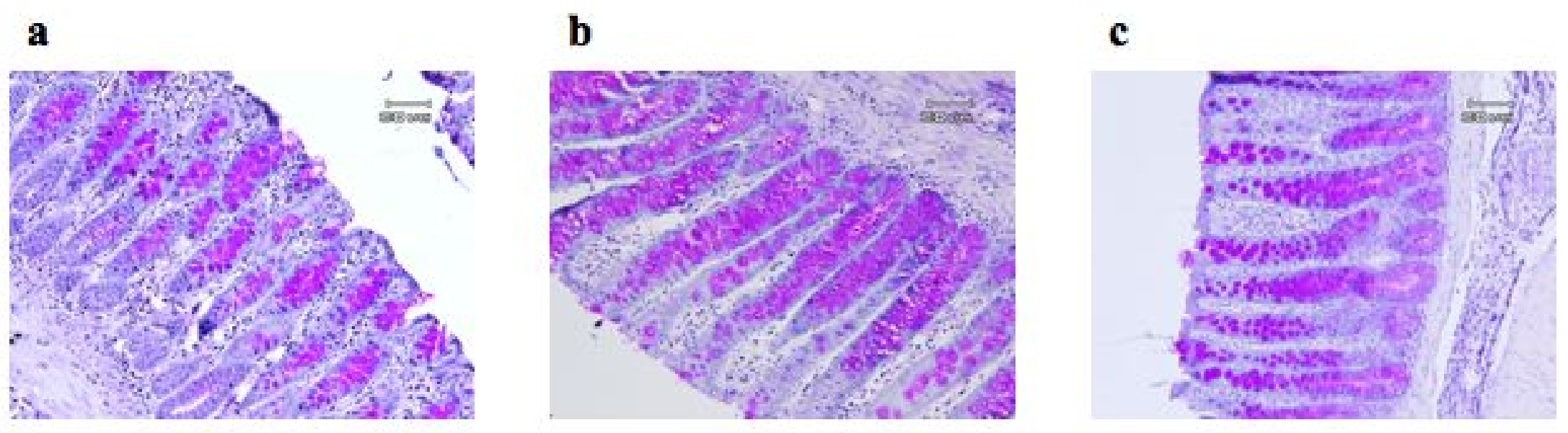

Fig.5 